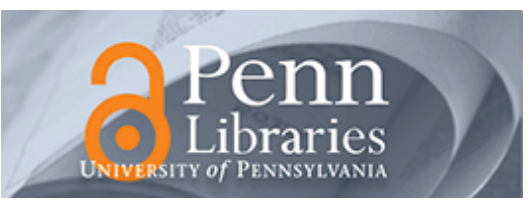

University of Pennsylvania

ScholarlyCommons

6-3-2011

\title{
In Situ Nanomechanical Testing in Focused lon Beam and Scanning Electron Microscopes
}

\author{
Daniel S. Gianola \\ University of Pennsylvania; Karlsruhe Institute of Technology, gianola@seas.upenn.edu \\ Andreas Sedlmayr \\ Karlsruhe Institute of Technology \\ Reiner Mönig \\ Karlsruhe Institute of Technology \\ Cynthia A. Volkert \\ University of Göttingen \\ Ryan C. Major \\ Hysitron, Inc. \\ Follow this and additional works at: https://repository.upenn.edu/mse_papers

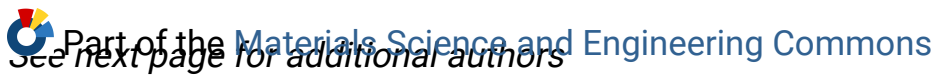

\section{Recommended Citation}

Gianola, D. S., Sedlmayr, A., Mönig, R., Volkert, C. A., Major, R. C., Cyrankowski, E., Asif, S. S., Warren, O. L., \& Kraft, O. (2011). In Situ Nanomechanical Testing in Focused Ion Beam and Scanning Electron Microscopes. Retrieved from https://repository.upenn.edu/mse_papers/205

Suggested Citation:

Gianola, D.S. et al.In situ nanomechanical testing in focused ion beam and scanning electron microscopes. Review of Scientific Instruments. 82, 063901.

(C) 2011 American Institute of Physics. This article may be downloaded for personal use only. Any other use requires prior permission of the author and the American Institute of Physics. The following article appeared in Review of Scientific Instruments. and may be found at http://dx.doi.org/10.1063/1.3595423

This paper is posted at ScholarlyCommons. https://repository.upenn.edu/mse_papers/205

For more information, please contact repository@pobox.upenn.edu. 


\title{
In Situ Nanomechanical Testing in Focused Ion Beam and Scanning Electron Microscopes
}

\author{
Abstract \\ The recent interest in size-dependent deformation of micro- and nanoscale materials has paralleled both \\ technological miniaturization and advancements in imaging and small-scale mechanical testing methods. \\ Here we describe a quantitative in situ nanomechanical testing approach adapted to a dualbeam focused \\ ion beam and scanning electron microscope. A transducer based on a three-plate capacitor system is \\ used for high-fidelity force and displacement measurements. Specimen manipulation, transfer, and \\ alignment are performed using a manipulator, independently controlled positioners, and the focused ion \\ beam. Gripping of specimens is achieved using electron-beam assisted Pt-organic deposition. Local \\ strain measurements are obtained using digital image correlation of electron images taken during testing. \\ Examples showing results for tensile testing of single-crystalline metallic nanowires and compression of \\ nanoporous Au pillars will be presented in the context of size effects on mechanical behavior and \\ highlight some of the challenges of conducting nanomechanical testing in vacuum environments.

\section{Disciplines} \\ Engineering | Materials Science and Engineering

\section{Comments} \\ Suggested Citation: \\ Gianola, D.S. et al.In situ nanomechanical testing in focused ion beam and scanning electron \\ microscopes. Review of Scientific Instruments. 82, 063901.
}

(C) 2011 American Institute of Physics. This article may be downloaded for personal use only. Any other use requires prior permission of the author and the American Institute of Physics. The following article appeared in Review of Scientific Instruments. and may be found at http://dx.doi.org/10.1063/1.3595423

\section{Author(s)}

Daniel S. Gianola, Andreas Sedlmayr, Reiner Mönig, Cynthia A. Volkert, Ryan C. Major, Edward Cyrankowski, S.A. Syed Asif, Oden L. Warren, and Oliver Kraft 


\title{
In situ nanomechanical testing in focused ion beam and scanning electron microscopes
}

\author{
D. S. Gianola, ${ }^{1,2}$ A. Sedlmayr, ${ }^{2}$ R. Mönig, ${ }^{2}$ C. A. Volkert, ${ }^{3}$ R. C. Major, ${ }^{4}$ E. Cyrankowski, ${ }^{4}$ \\ S. A. S. Asif, ${ }^{4}$ O. L. Warren, ${ }^{4}$ and O. Kraft ${ }^{2}$ \\ ${ }^{1}$ Department of Materials Science and Engineering, University of Pennsylvania, Philadelphia, Pennsylvania \\ 19104, USA \\ ${ }^{2}$ Institute for Applied Materials, Karlsruhe Institute of Technology, Karlsruhe, Germany \\ ${ }^{3}$ Institute for Materials Physics, Georg-August University of Göttingen, Göttingen, Germany \\ ${ }^{4}$ Hysitron, Inc., Minneapolis, Minnesota 55344, USA
}

(Received 12 February 2011; accepted 5 May 2011; published online 3 June 2011)

\begin{abstract}
The recent interest in size-dependent deformation of micro- and nanoscale materials has paralleled both technological miniaturization and advancements in imaging and small-scale mechanical testing methods. Here we describe a quantitative in situ nanomechanical testing approach adapted to a dualbeam focused ion beam and scanning electron microscope. A transducer based on a three-plate capacitor system is used for high-fidelity force and displacement measurements. Specimen manipulation, transfer, and alignment are performed using a manipulator, independently controlled positioners, and the focused ion beam. Gripping of specimens is achieved using electron-beam assisted Pt-organic deposition. Local strain measurements are obtained using digital image correlation of electron images taken during testing. Examples showing results for tensile testing of single-crystalline metallic nanowires and compression of nanoporous Au pillars will be presented in the context of size effects on mechanical behavior and highlight some of the challenges of conducting nanomechanical testing in vacuum environments. ( 2011 American Institute of Physics. [doi:10.1063/1.3595423]
\end{abstract}

\section{INTRODUCTION AND BACKGROUND}

As technological devices continue to miniaturize and the constituent materials that comprise them approach micro- and nanoscale dimensions, the need for accurate scale-specific testing methods grows. The mechanical behavior of microand nanoscaled materials has in particular been the subject of recent interest, borne from the importance of structural integrity in next-generation small-scale devices, as well as the emergence of size effects on mechanical behavior. The latter discovery has motivated a number of studies that revealed that the mechanical behavior of small crystals is markedly different than that of their bulk counterparts. ${ }^{1-14}$ These driving forces have necessitated the development of new techniques and testing methods that address the difficulties of synthesizing, handling, and measuring properties of micro- and nanoscaled specimens. ${ }^{15}$ Techniques ranging from nanoindentation, ${ }^{16}$ micro- and nanocompression, ${ }^{17-19}$ microbending, $, 511,20-22$ and micro- and nanotension ${ }^{8,23-36}$ have been introduced using novel instrumentation and analysis approaches.

In parallel, a large surge of effort has focused on in situ methodologies, where imaging and testing occur simultaneously. ${ }^{37}$ Imaging and characterization platforms with requisite spatial resolution for nanoscale investigations that have been employed for in situ mechanical testing include scanning electron microscopy (SEM), ${ }^{17,28,36,38-40}$ transmission electron microscopy (TEM), ${ }^{41-53}$ atomic force microscopy (AFM), ${ }^{32,54}$ micro-beam X-ray diffraction, ${ }^{55-57}$ and visible light scattering (e.g., Raman spectroscopy). ${ }^{55,58}$ While high-throughput in situ testing is still nascent, one advantage of such testing is clear; a correlation between deforma- tion events and measurement of properties can be directly obtained. Despite the new approaches that have been developed to address small scale mechanical testing, not all are fully quantitative and many result in data fraught with uncertainty. Given the technological advances in high-fidelity sensors, actuators, and positioners, a strong thrust towards developing or refining testing techniques and standardization that mitigate experimental error and artifacts must be accomplished; these demands were successfully addressed for large scale mechanical testing (see, e.g., Ref. 59) and should be used as a guide for small scale measurements. A comparison of several smallscale mechanical testing approaches ${ }^{23,35,60-71}$ is summarized in Fig. 1, where the dynamic range in both displacement and force measurement is highlighted.

In this work, we introduce a novel in situ nanomechanical testing platform consisting of a parallel-plate capacitor system for actuation and displacement measurement, and nanopositioning stages for proper specimen alignment. The system is capable of a wide range of nanomechanical tests, including nominally uniaxial tension and compression, nanoindentation, and bending. Rzepiejewska-Malyska et al. recently reported the development of a nanoindentation system capable of being operated in an SEM environment. ${ }^{38}$ We report the modification and operation of a next-generation transducer and extend the application to nanotensile and microcompression testing in a dual-beam focused ion beam (FIB) and SEM instrument. Special attention is placed on methods required for nanotensile specimen preparation, forcedisplacement transducer operating principles, vacuum compatibility of the instrument, and the use of quantitative digital imaging methods. We show the efficacy of this instrumentation by way of two representative examples that highlight the 

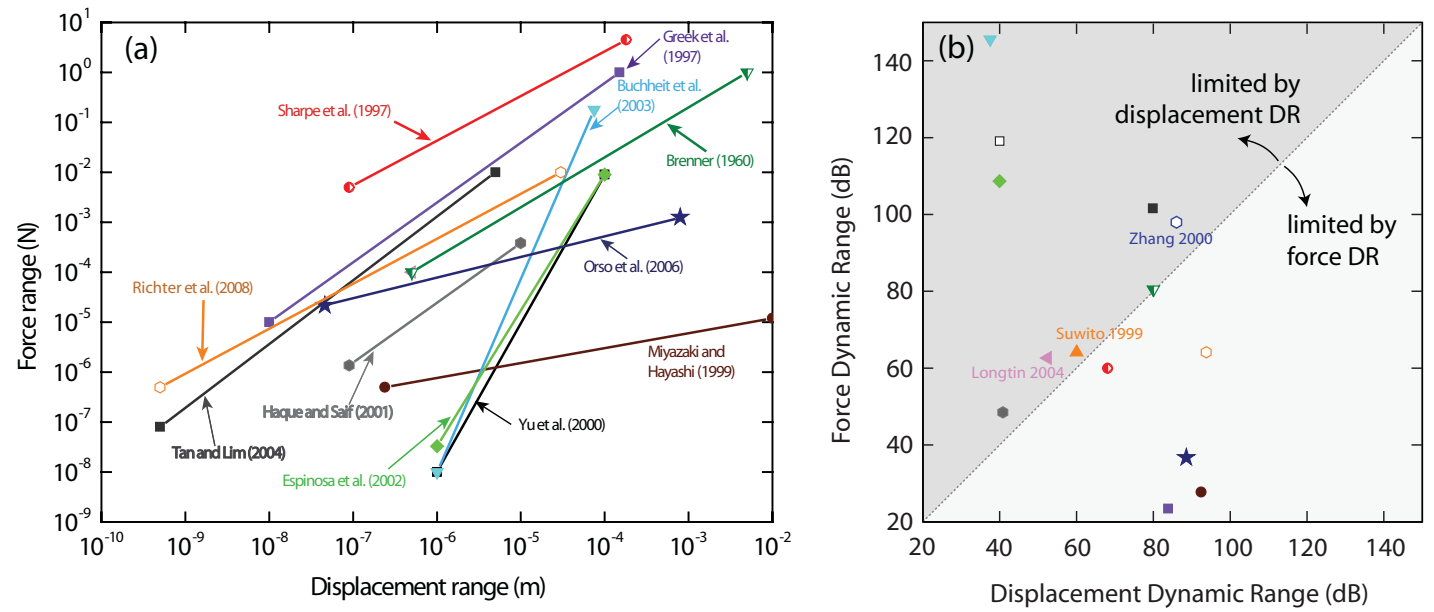

FIG. 1. (Color online) Force versus displacement range offered by a variety of small-scale tensile testing techniques (Refs. 23 and 35, and 60-71). (a) The lower point represents the resolution of the system, while the upper point is the maximum allowable value. (b) Force and displacement dynamic ranges of testing techniques. We use the conventional definition of dynamic range, where $\mathrm{DR}=20 \times \log$ (maxvalue/noisefloor), plotted in $\mathrm{dB}$. The symbols correspond to the lines shown in (a) except for those labeled.

ability of these methods for interrogation of single crystal deformation behavior at small length scales: (i) tensile testing of single-crystalline metallic nanowires and (ii) microcompression testing of nanoporous $\mathrm{Au}$.

\section{EXPERIMENTAL}

\section{A. Background of methods for in situ nanomechanical testing}

When the dimensions of testing specimens are decreased to the nanoscale, there is also need for different techniques that facilitate accurate and readily interpretable testing. White light optical microscopy is no longer sufficient as the imaging platform at these scales due to diffraction-limited spatial resolution and is often replaced by electron beam imaging of the small specimens. Gas injection systems inside the SEM can be used for gripping the specimens in lieu of mechanical clamps. Manipulation also needs to be done inside the SEM and remotely, using devices that allow for fine motion of the order of atomic spacing, but with large overall range. Imaging and manipulation techniques are also crucial for the alignment of the specimens in order to achieve nom-
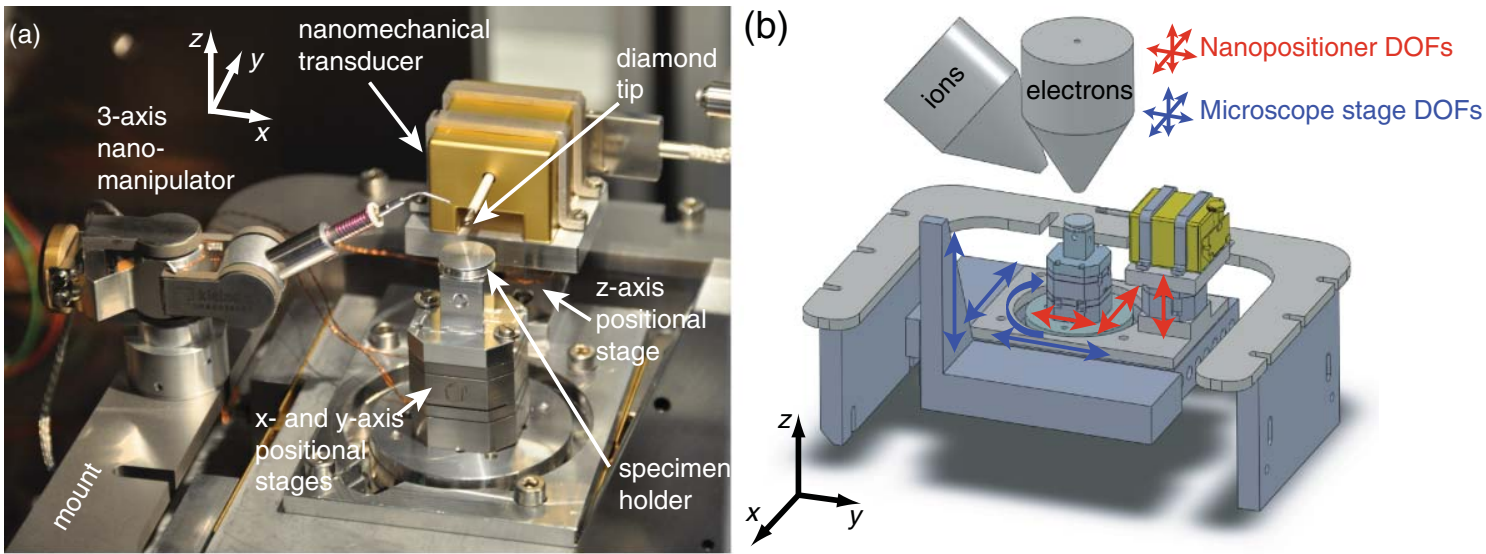

(c)

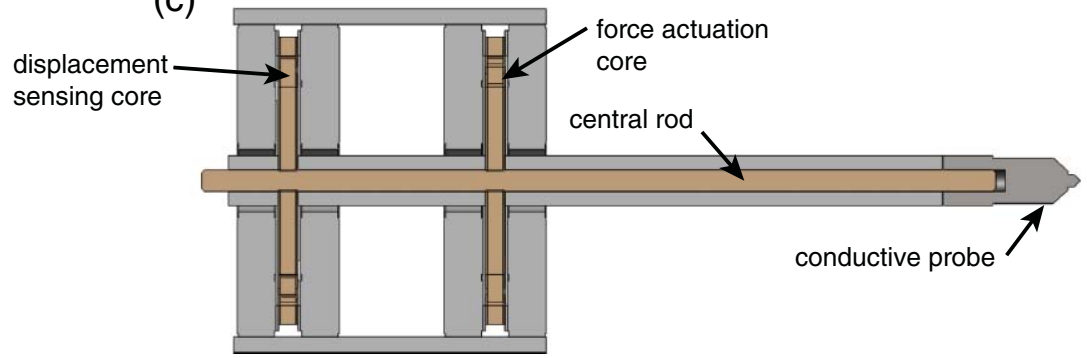

FIG. 2. (Color online) Nanomechanical testing setup. (a) Image of the assembly in the vacuum chamber of the dual-beam FIB/SEM. The transducer, manipulator, and nanopositioners are arranged in a configuration that allows for sufficient range of motion and modular installation of the components. (b) Schematic of the setup highlighting the DOF of motion available from the nanopositioning and microscope stages. Note that the nanomanipulator is not shown in (b). (c) Crosssectional diagram of the nanomechanical transducer. 
inally uniaxial testing conditions and allowing for facile data interpretation.

The in situ nanomechanical testing platform reported here employs a FIB/SEM dual-beam system equipped with a transducer based upon a double three-plate capacitor design, ${ }^{38}$ a nanomanipulator, and three independently controlled nanopositioners. A photograph and a schematic showing all degrees of positioning freedom are shown in Fig. 2. In Secs. II B-II D, we describe the main experimental components and approaches.

\section{B. Nanostructure harvesting, manipulation, transfer, alignment, and gripping}

The first task in performing a nanomechanical test is to identify and isolate a single specimen. In the case of nanoindentation and microcompression, for instance, this involves locating an area that has been previously prepared by standard metallographic techniques or using other techniques to fabricate specimens. In the case of nanoscale tensile testing, specimens are often dispersed randomly or grown in high density on a substrate, requiring careful harvesting of individual specimens. We now focus on an example of extracting an individual nanowire for subsequent tensile testing as shown in Fig. 3. A standard SEM holder can be used to mount the sample with synthesized nanostructures, as well as a well-defined gripping substrate. Once a specimen that meets the desired dimensions is identified, it is aligned with the microscope stage such that it can be approached and gripped easily with the manipulator (Fig. 3(a)). The root of the specimen is brought into close proximity with the nanomanipulator tip (Kleindiek Nanotechnik) using a combination of stage and coarse manipulator motion (Fig. 3(b)). Contact between the manipulator and tip can be ensured by: (i) a change in contrast due to electrical contact, (ii) small mechanical perturbations of the manipulator, or (iii) changes in the vibration response of the specimen due to new boundary conditions. All of these methods minimize mechanical loads applied to the specimen, particularly if the tip is attached at the root of a nanowire. The specimen is then "glued" to the tip of the manipulator using local electron-beam induced deposition (EBID) of a Pt-based organometallic precursor gas that is delivered through an injection system and adsorbs to nearby surfaces ${ }^{72-75}$ Given that the initial attachment point is near the root of the nanowire, any mechanical deformation would occur between the tip and the root; the free end of the wire is stress free. This point is exploited for detachment of the wire from the substrate by small movements of the manipulator or microscope stage. Provided that the bonding of the Pt-organic deposit is strong relative to the substrate-wire interface, the wire will break off leaving a freestanding nanowire attached to the manipulator tip (Fig. 3(b)). Alternatively, the manipulator tip can be attached at the end of the nanowire and the root can be cut free using the FIB. However, this method is avoided in cases where the influence of the ion beam is expected to have an adverse effect on mechanical response. ${ }^{76}$

Alignment of the nanowire with the first gripping surface must then be achieved (Fig. 3(c)). Precise alignment involves ensuring coincidence of the nanowire and actuation and force measurement axes, which can be challenging. Multiple degrees of freedom (DOF) of stage and manipulator are required, as well as proper characterization of the spatial orientation of the specimen from its growth substrate. Given the difficulty of mitigating misorientation out of the image plane, we employ an AFM cantilever as our fixed gripping surface, which provides ample in-plane stiffness while exhibiting appreciable out-of-plane compliance (bending of the cantilever about its transverse axis). The efficacy of this approach in eliminating misalignment issues depends on the degree of misalignment and the relative stiffness of the specimen being tested. Nevertheless, the location of fracture can be used as a gauge; fracture near the grips implies significant concentration of stress, while fracture in the middle of the specimen indicates good alignment. Only data from the latter events are used when reporting tensile strength values. Bringing the cantilever and the free end of the specimen into aligned contact is accomplished using the microscope stage and manipulator. Local Pt-organic EBID is applied once more for
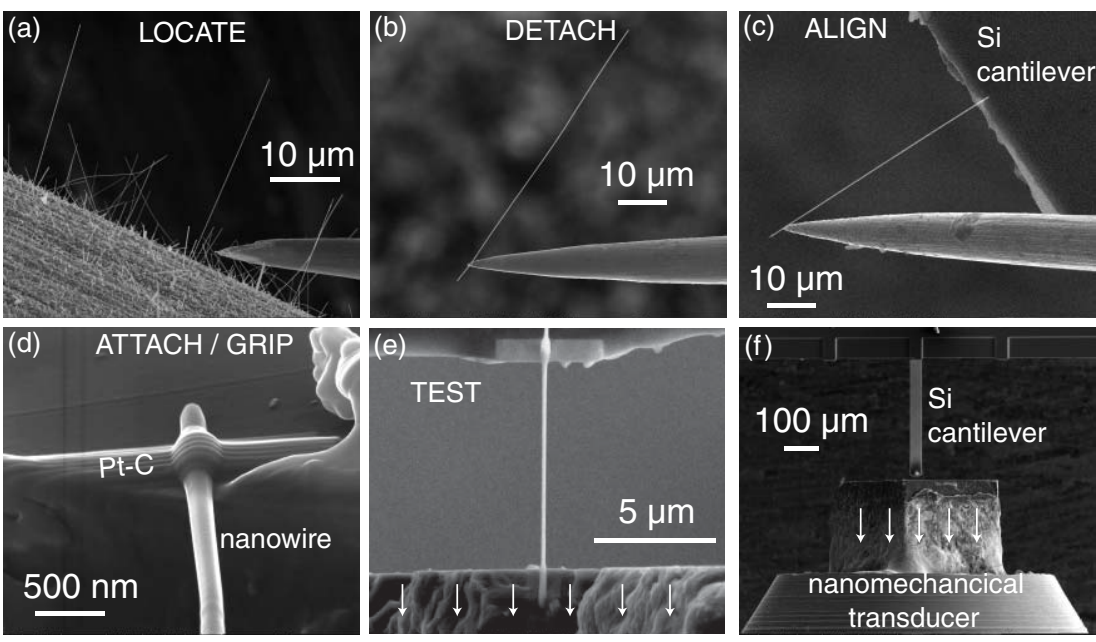

FIG. 3. SEM images showing the steps required to harvest quasi-1D nanostructures for mechanical testing. The sequence of manipulation, transfer, alignment, gripping, and tensile testing of nanowire specimen is shown. (f) A low-magnification image of the testing configuration showing the diamond tip attached to the transducer (bottom) as well as the fixed grip (top). The nanowire specimen is barely visible in the center of the image. 
gripping. Subsequently, the specimen is cut free from the manipulator tip on the opposite side using the FIB and the manipulator is retracted. It should be noted that very small beam currents $(<10 \mathrm{pA})$ are used for these cutting processes and the cut area of the specimen is never included in the gauge section of the specimen.

In the case of microcompression testing, the end effector on the transducer is changed to a flat-punch diamond tip, which is brought into contact with pillar specimens fabricated directly on the sample, similar to other reported in situ microcompression methods. ${ }^{19,57,77}$ Following Ref. 78, we check for alignment of the tip with respect to the pillar axis by performing low-load indentations on the sample surface slightly away from the micropillars. The residual imprint left from plastically deforming the sample surface and any corresponding asymmetry gives an indication of the degree of misalignment. Any detected misalignment is corrected for using the degrees of freedom of the testing system. We note that the two orthogonal tilt axes (one is provided by the SEM rotational stage) necessary for accurate alignment of the punch to the specimen surface are not available, though since the pillars are fabricated directly on the SEM stub, the misalignment in the second tilt direction is expected to be small. We estimate such misalignment to be $<5^{\circ}$, which corresponds to an uncertainty in the axial force measurement of $<0.5 \%$.

As shown in Fig. 3(d), the Pt-organic deposits used for gripping of the two ends of the nanowire tensile specimens provide a conformal coating that attaches the specimen to the gripping surface. All deposits were performed using the electron beam as the energy source for the molecular dissociation, at energies of $10 \mathrm{kV}$ while varying the beam dwell time and deposit area depending on the material and size. Limited information exists regarding the strength of these "tape" deposits given that the microstructure and corresponding properties vary depending on the deposition conditions. Nevertheless, this gripping method has proven to be sufficiently strong for specimens as large as several $\mu \mathrm{m}$, generating forces as high as $\sim 5 \mathrm{mN} .{ }^{35}$ Specimens that have diameters that are larger than $\sim 0.5 \mu \mathrm{m}$ and have high strengths need to be gripped strongly to avoid slipping at the gripping ends. In these instances, we have employed two reinforcing methods: (i) FIB milling of a recessed gripping surface in order to provide a strong interfacial bond between the Pt-organic deposits and the specimen which sits in this machined trough, or (ii) depositing multiple strips both aligned perpendicular and at $45^{\circ}$ angles to the tensile axis so as to maximize the resistance of the grips in shear.

It should be noted that the Pt-organic deposits, although locally attached to the ends of long nanowire specimens, have been known to show significant delocalization and can decorate surfaces away from the region of electron rastering during deposition. The extent of the spread of EBID deposits was experimentally shown by Gopal $\mathrm{et} \mathrm{al}$. to have a diameter exceeding $10 \mu \mathrm{m}$ on oxidized silicon, and was attributed to thermally assisted diffusion of $\mathrm{Pt}$ on the surface. ${ }^{79}$ Such a mechanism implies that the extent of delocalization will depend strongly on the diffusive and thermal properties of the material being studied. We have examined single crystalline $\mathrm{Cu}$ nanowires in TEM after depositing Pt-organic grips on either side, where electron dispersive spectroscopy shows minimal Pt-organic delocalization above the detection limit in the gauge section of the specimen. Nevertheless, other materials could potentially show enhanced diffusion of the Pt-organic species, resulting in decoration of the nanostructure being tested. Thus, caution should be taken to characterize the role of a Pt-organic sheath on load bearing behavior during mechanical testing of nanostructures. Following measurements of the strength and stiffness of ion-beam induced deposition of Pt-organic by Utke et al., ${ }^{80}$ we make the following rough estimate of the effect of a Pt-organic shell surrounding a copper nanowire core. Assuming an iso-strain deformation (Voigt composite) configuration, we can calculate an upper limit of the effect on measurements of the Young's modulus of a nanowire as follows. We write the effective modulus $E_{\text {eff }}$ of such a composite as $E_{e f f}=E_{P t-C} v_{f}+E_{N W}\left(1-v_{f}\right)$, where $E_{P t-C}$ is the Young's modulus of the Pt-organic deposit, $E_{N W}$ is the Young's modulus of the nanowire, and $v_{f}$ is the volume fraction of the Pt-organic shell. For a cylindrical core-shell geometry, we can express $v_{f}$ as $v_{f}=(t / d(1+t / d)) /(1 / 4$ $+t / d(1+t / d))$, where $t$ is the thickness of the shell and $d$ is the diameter of the nanowire core. Assuming a modulus ratio $E_{P t-C} / E_{N W}=0.1$, which is reasonable for analysis of a metallic nanowire, ${ }^{80}$ the effective modulus of the composite would change by more than $10 \%$ (sufficiently beyond experimental uncertainty such as to be detected) if $t / d>1 / 33$. For instance, a $3 \mathrm{~nm}$ Pt-organic coating on a $100 \mathrm{~nm}$ Cu nanowire would change the effective Young's modulus by $\sim 10 \%$. Thus, an increasing effect on load bearing of the Pt-organic layer is expected with decreasing nanowire diameter. Nevertheless, when the diameter of the nanowire without the shell can be accurately measured prior to contamination, a good estimate of engineering stress is possible in cases where the relative shell size is small.

The final step in the preparation of our in situ nanowire tensile test is to align and move the nanomechanical transducer tip to the specimen using the three-axis nanopositioning system (Attocube Systems) and the rotational axis of the microscope stage (as illustrated in Fig. 2). Once the free end has made contact with a conductive diamond tip at the distal end of the transducer, Pt-organic is once again deposited to fully secure the nanowire in place for a mechanical test as shown in Figs. 3(e) and 3(f).

\section{Load application and measurement}

\section{Transducer details}

The heart of any nanomechanical test system is the transducer. To quantitatively measure nanomechanical properties, it is imperative that the transducer itself be well characterized and calibrated in order to achieve accurate force and displacement measurements. The transducer used for the current system is similar in concept to the one used previously by Rzepiejewska-Malyska et al. ${ }^{38}$ The transducer is capable of both electrostatic force actuation and capacitive displacement sensing. A cross-sectional view of the transducer is shown in Fig. 2(c). Similar to the transducer described previously, ${ }^{38}$ this current design includes two sensor cores both coupled 
(a)

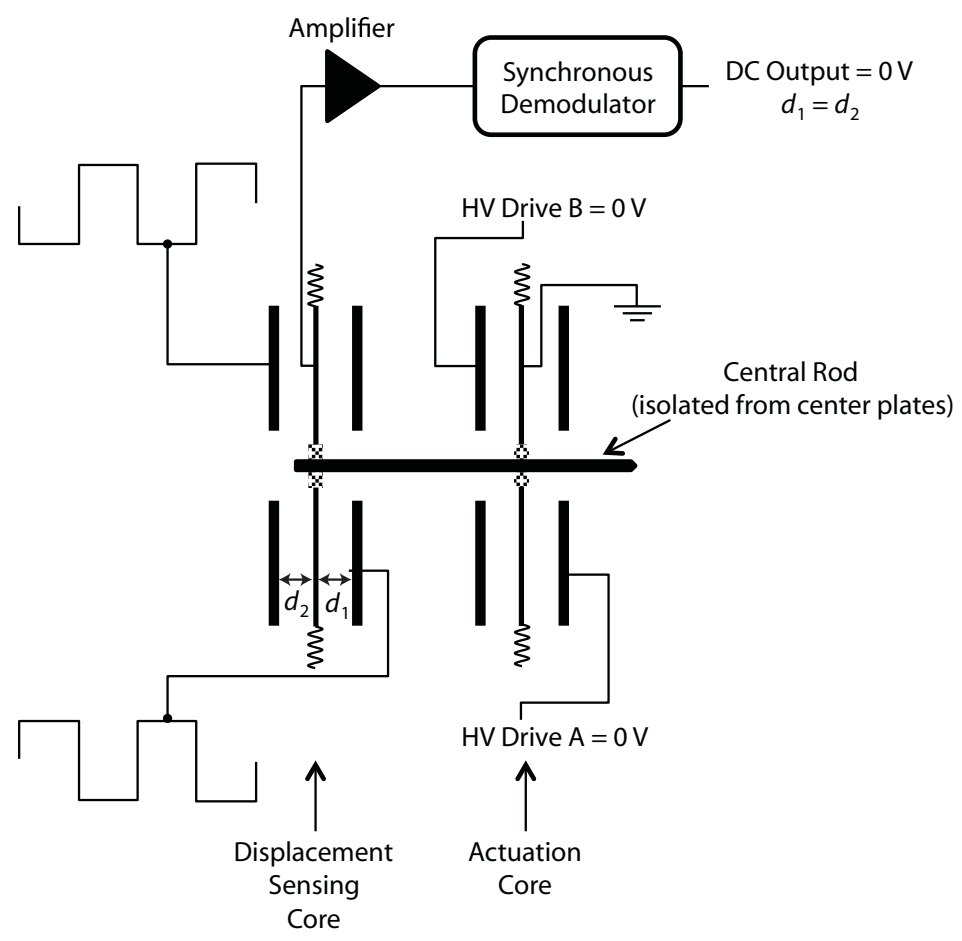

(b)

HV Drive A Activated Indentation/Compression Mode

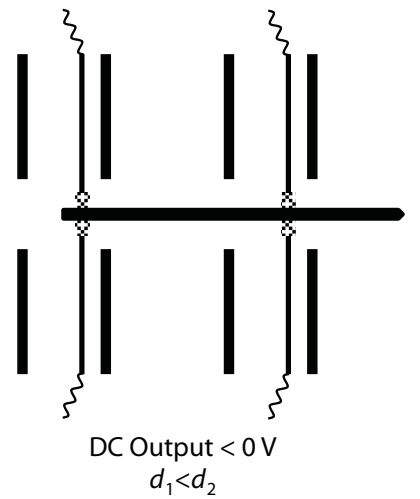

(c)

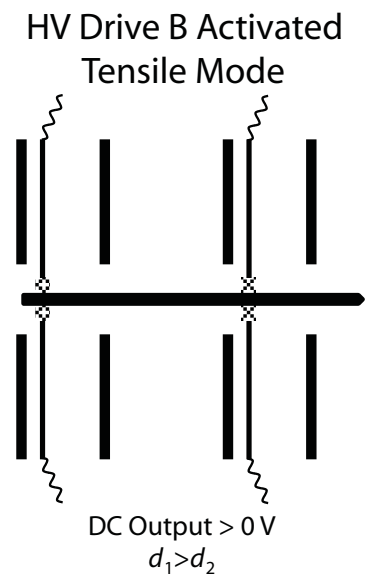

FIG. 4. A schematic representation of the transducer operating principles. (a) The two three-plate sensor cores are shown in the horizontal orientation with the center plates evenly centered between the outer plates (theoretical rest position). An electrostatic actuation force for indentation/compression or tensile modes is generated by applying a DC voltage to the front (b) or rear (c) outer plate of the actuation core, respectively. Note: For illustrative purposes, the center plate movement has been exaggerated relative to the overall gap dimension in (b) and (c).

to a central rod. Each sensor core is based upon a threeplate capacitor design consisting of a spring suspended center plate (center electrode), which occupies the space between two fixed outer plates. Dielectric spacers are used to maintain parallel configuration of the three plates. The nominal gap between the center plate and either outer plate is 100 $\mu \mathrm{m}$. The central rod is directly coupled to the center plate of each sensor core. The central rod consists of a ceramic outer sheath surrounding a threaded brass rod. The ceramic sheath provides electrical isolation of the rod from the center plates. The sensor core closest to the probe is used to generate the actuation force and the second core is used for displacement sensing only. The conductive probes are designed to be interchangeable and are attached by simply threading onto the central rod. The probes can be constructed out of various conductive (and non-conductive) materials and machined to meet the desired application. The standard tips are made of single crystal boron doped diamond with a nominal resistivity of $0.04 \Omega \mathrm{m}$. The doping is implemented during the diamond growth process, which gives a more homogenous doping profile compared to surface doping methods. In order to prevent electrostatic charge buildup on the probe from the electron beam, a conduction path through the central rod is provided.
Electrostatic actuation is achieved by applying a known DC voltage between the center and one of the outer plates. The transducer operating principles are illustrated in Fig. 4. This next generation transducer is larger than the one used by Rzepiejewska-Malyska et al., ${ }^{38}$ and is capable of bidirectional actuation depending on which outer plate is activated during the test (Figs. 4(b) and 4(c)). The larger transducer design is able to generate nearly $10 \mathrm{mN}$ of force with a displacement range of $\pm 15 \mu \mathrm{m}$. The electrostatic force, $F_{\mathrm{e}}$, generated by the electrostatic actuation is described by the following equation:

$$
F_{e}=\frac{\varepsilon_{0} A}{2 d_{0}^{2}} \frac{1}{\left(1-\delta / d_{0}\right)^{2}} V^{2}=\frac{\kappa_{0}}{\left(1-\delta / d_{0}\right)^{2}} V^{2},
$$

where $\varepsilon_{0}$ is the electrical permittivity, $A$ is the overlapping electrode area, $d_{0}$ is the nominal electrode gap (i.e., gap when no voltage is applied), $\delta$ is the displacement from $d_{0}, \kappa_{0}$ is the electrostatic force constant at the nominal gap, and $V$ is the voltage applied across the center plate and outer electrode. As described with Eq. (1), the electrostatic force is proportional to $V^{2}$ and inversely proportional to the square of the capacitor plate gap. To achieve bi-directional actuation, the excitation voltage must be directed to either the front or rear outer plate depending upon whether the desired test is compressive or 
tensile, respectively (see Figs. 4(b) and 4(c)). During the test, the gap between the center and outer electrodes will change which will in turn result in a change to the electrostatic force. Equation (1) takes into account this change in electrode gap.

To detect displacements, a ratiometric method is used involving a high frequency ( $\sim 125 \mathrm{kHz}$ square wave) signal on one of the fixed outer plates and a second signal of the same frequency but phase shifted by $180^{\circ}$ on the other outer plate. The high frequency signal is much higher than the mechanical bandwidth of the transducer $(\sim 100 \mathrm{~Hz})$ and, consequently, the high frequency voltages applied for the sensing do not actuate the transducer. In the three-plate capacitor design, each outer plate and center plate combination can be considered as a separate capacitor (with capacitances $C_{1}$ and $C_{2}$ ). As the center plate moves, a high impedance pre-amplifier circuit is used to measure the change in capacitance. The pre-amplifier circuit is designed to produce a DC voltage output proportional to the displacement. In the absence of stray capacitance, the voltage output $V_{\text {out }}$ from the sensor is proportional to the capacitance ratio as described with the following equation:

$$
V_{\text {out }} \propto \frac{C_{2}-C_{1}}{C_{1}+C_{2}},
$$

where $C_{1}$ and $C_{2}$ are the two capacitances in the differential capacitance sensing.

In order to minimize pump down time, only high vacuum or ultra-high vacuum compatible materials were incorporated into the design. Components containing magnetic impurities were also avoided to prevent interference with the electron beam and/or electron imaging.

\section{Calibration}

The displacement calibration is done over a range of $\pm 15 \mu \mathrm{m}$ with the transducer mounted horizontally, which is the typical operational orientation for compression/tensile test modes. In this orientation, the voltage output of the transducer was determined to be linear with a linearity error of $<1 \%$ over this range. Calibration of the spring stiffness of the transducer $(k=362 \mathrm{~N} / \mathrm{m})$ involves using certified deadweights and laser interferometry with the transducer mounted in a vertical orientation. In this position, the center plate is offset by $\sim 20 \mu \mathrm{m}$ relative to the horizontal rest position. Finite element analysis of the transducer design indicated that the spring stiffness should be constant over displacements of at least $\pm 25 \mu \mathrm{m}$ about the relaxed state of the horizontal configuration. Therefore, the measured spring stiffness in the vertical orientation should be valid for the horizontal orientation. Before testing and at regular intervals, the zero-volt electrostatic force constant, $\kappa_{0}$, and the zero-volt rest gap $d_{0}$, are determined from a large displacement actuation with the tip out of sample contact (see Eq. (1)). During this test the electrostatic force generated, $F_{\mathrm{e}}$, must be equal to $k \delta$ based upon a linear spring model. This out-of-contact calibration is integrated into the software, which makes the task relatively quick and routine. The linearity error of the out-of-contact force-displacement curve (and thus the spring constant) was determined to be $<1 \%$ over the calibrated range of the transducer. The force calibration was also verified by testing with a reference transducer as well indenting against a flexure device of known spring constant. The displacement calibration was verified by both a reference transducer as well as SEM observation. Each actuation direction requires its own displacement and electrostatic force calibration.

For certain tests the transducer and sample may be tilted with respect to the electron beam in order to better view the contact zone during the test. The maximum possible tilt is about $30^{\circ}$ for this system. At higher tilt angles there is the risk of collision between the transducer housing and the electron column. The maximum tilt angle will vary based upon SEM manufacturer, chamber design, and orientation of the nanomechanical test instrument relative to the tilt axis of the SEM. Also, the number and placement of auxiliary components (e.g., detectors, manipulators, gas injection needles, etc.) on the chamber may restrict movement. As the transducer is tilted, the weight of the center plate/central rod assembly causes a "forward" displacement shift. The calibrated range of $\pm 15 \mu \mathrm{m}$ is referenced to the relaxed state of the horizontal configuration. For a tilt angle of $30^{\circ}$, the center plate will be offset by $\sim 10 \mu \mathrm{m}$. In order to stay within the calibrated working range of the transducer, the maximum displacement in the forward direction will be reduced by the offset. This travel range is restricted by software control. The electrostatic force calibration routine should also be repeated if the orientation of the transducer changes (e.g., transducer tilted). Improved calibration methods are currently being explored to increase the calibrated range of travel.

\section{Control system and feedback operation}

A recently developed digital signal processor (DSP) based controller and data acquisition system (performech ${ }^{\mathrm{TM}}$, Hysitron, Inc.) was utilized for nanomechanical test control. The controller interfaces to a PC through a USB 2.0 link. The controller includes 24-bit ADCs and 16-bit DACs for analog signal acquisition and analog output, respectively. The DSP architecture is ideally suited for the calculation of intensive algorithms implemented for the various transducer control and test modes. There are three basic control modes used to operate the transducer, which include open-loop load ramp, closed-loop displacement control with displacement set point ramp and true closed-loop load control. ${ }^{81}$ The control modes can be used to operate the transducer in either direction depending upon whether the desired test is tensile or indentation/compression related. Prior to the test, the user defines a load or displacement versus time function, which is then transferred to the DSP controller. Once the test is initiated, the DSP controller implements the necessary feedback algorithms and performs all calculations required for real-time control. The internal loop cycle runs at $79 \mathrm{kHz}$, and the controller handles additional signal processing (e.g., data averaging, filtering, etc.) within the loop cycle.

\section{Noise in in situ systems}

For accurate results in nanomechanical testing, the presence of noise in the system should be minimized. The 

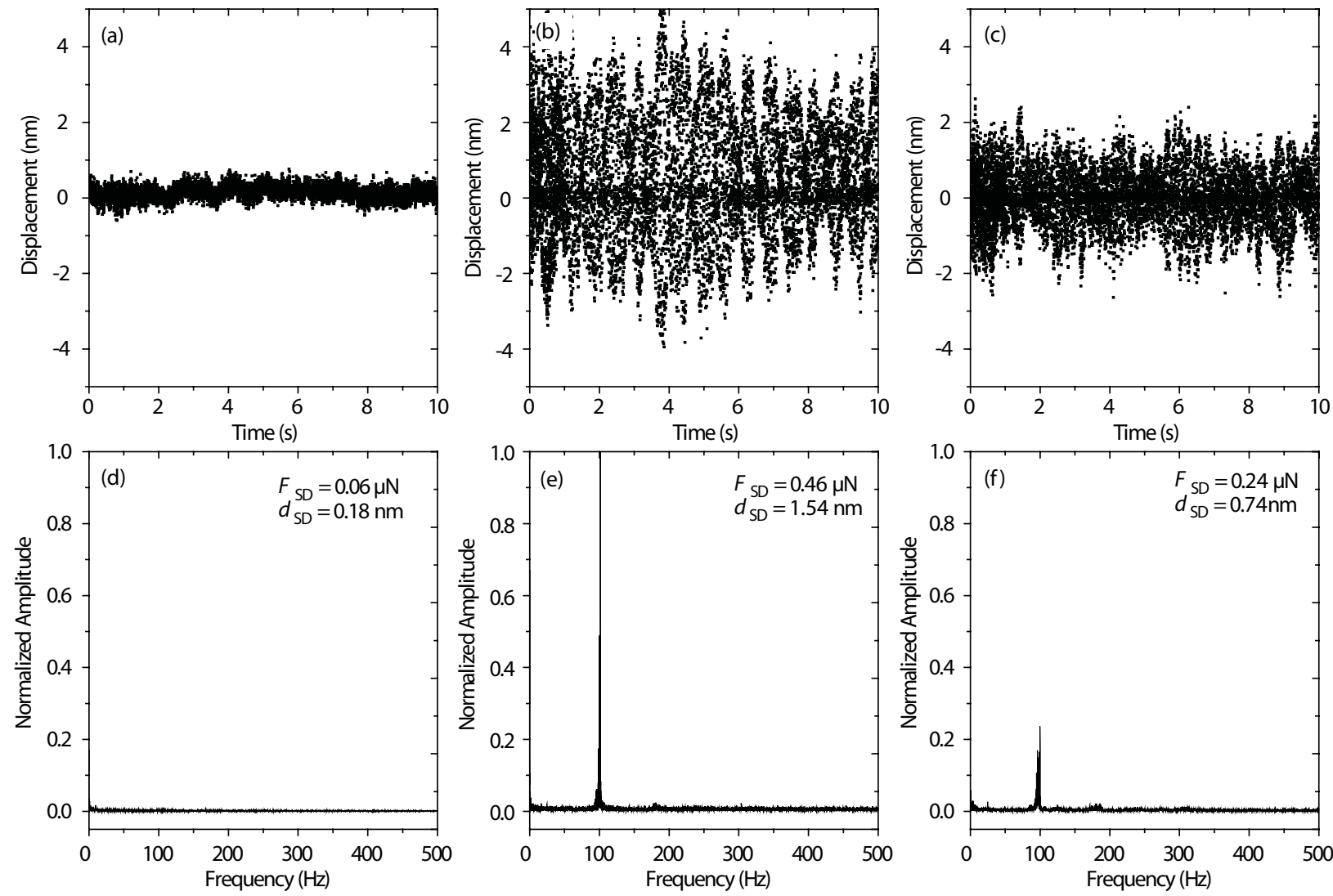

FIG. 5. Noise characteristics in air and in vacuum, revealing the different noise floors for open-loop mode in air (a), in vacuum (b), and for Q-control enabled mode in vacuum (c). The corresponding frequency response (d, e, and f) shows significant amplitude differences in mechanical resonance, which is $\sim 100 \mathrm{~Hz}$ for the transducer assembly. The force and displacement noise floors for the different configurations are included.

occurrence of noise in a raw output signal can have many origins, particularly, in vacuum environments, such as: (i) mechanical vibrations, (ii) electrical noise from the ac line source (with characteristic frequencies), and (iii) electrical noise from stray electromagnetic fields. Strategies for eliminating the presence of these deleterious effects can be generally characterized as those preventing the origin of the noise or those that actively compensate.

To reduce the noise and hence improve the performance of the system, the mechanical design of the system should be optimized to reduce the transfer of external noise to the system. Two main aspects have to be considered here: (i) the mechanical connection between the microscope mechanical stage and transducer should be as stiff as possible and (ii) the entire system should be isolated from external vibrations. The latter is fulfilled by the pneumatic isolation of the microscope chamber from the ground. Besides mechanical measures, suitable algorithms implemented in the control hardware and software of the transducer are used to dampen out a significant part of the noise that is caused by mechanical resonance.

The nanomechanical transducer is designed for operation in both ambient and high vacuum environments. In a high vacuum/low air damping environment, there is an increase in the mechanical amplification at the resonance frequency and an increase in the overall settling time of the transducer. Figure 5 shows the differences of the system if operated in air or vacuum. The time domain in Fig. 5(a) and the corresponding fast Fourier transform (FFT) in Fig. 5(d) display the noise level when the transducer is operated in open-loop air mode. By bringing the transducer into vacuum, the open-loop noise floor in Fig. 5(b) is increased by a factor of 8. The FFT spectrum in Fig. 5(e) shows a large peak around $100 \mathrm{~Hz}$, indicating that the transducer is oscillating at its resonance frequency.

In addition to long settling times while operating in open-loop control mode, the closed-loop control of the test may become quite unstable due to this effect. To solve the problems inherent in performing nanomechanical testing in a high vacuum environment, increasing the system damping is highly desired. Reducing the system quality factor in high vacuum can shorten the settling time and improve the stability for closed-loop control. Due to this reason, a digital damping control algorithm has been implemented into the control system. ${ }^{82}$ The control algorithm is implemented by adding an additional signal to the actuation drive output sent to the transducer. This additional signal is calculated by multiplying the user-adjustable damping control gain by the $90^{\circ}$ phase shifted transducer displacement signal. All calculations are performed in real time by the DSP controller. The implemented damping control can either increase or decrease the system quality factor by manipulating the damping controller gain. Figures 5(c) and 5(f) show the noise characteristics for the configuration in vacuum with Q-control switched on. Compared to the open-loop spectrum in vacuum, the noise floor is reduced by a factor of 2 and the resonance peak diminished considerably. 


\section{Local strain measurement}

To perform accurate uniaxial mechanical testing capable of capturing all mechanical properties (e.g., Young's modulus, strength, and toughness), a local and non-contact approach for strain measurement must be employed. Given the inherent compliance of high-fidelity sensors and gripping modes used in micro- and nanomechanical testing, a remote displacement measurement and knowledge of the specimen gauge length is generally not sufficient to deduce the real specimen strain and can often lead to inaccurate stress-strain curves. We employed digital image correlation (DIC) of SEM images captured during in situ deformation experiments to calculate the local strain in the specimen. This technique, commonly applied to macroscale testing, ${ }^{83-88}$ has recently been extended to the micro- and nanoscale where conventional imaging schemes are replaced by SEM, ${ }^{36,89-92}$ FIB, ${ }^{35}$ and AFM (Ref. 32) platforms. Strain calculations using DIC rely on intensity variations in digital images, which can be present either naturally or intentionally via surface decoration or microfabrication methods. Sutton and co-workers reported a handful of approaches to introduce contrast in SEM images for DIC, ${ }^{93}$ as well as correction schemes to account for imaging artifacts and aberrations. ${ }^{90,91}$ We utilized natural contrast during nanowire tensile testing, which allows for comparison of image series obtained as a function of deformation. Briefly, DIC calculates the correlation coefficients of subsets of consecutive images. Determining the maximum of the correlation coefficient with varying deformation allows one to deduce the optimal mapping from a reference (undeformed) to a deformed state with sub-pixel precision. This approach is described in detail in Ref. 83. Since the calculation of strain depends on the acquisition of digital images, a compromise must be made between high and low imaging rates. The former allows for a faster data rate, which can be useful if dynamic mechanical response is expected or fast strain rates are needed. The latter, however, allows for a high electron beam dwell time, which enhances the signal-to-noise ratio resulting in higher quality images and lower noise in the strain calculation.

\section{REPRESENTATIVE RESULTS}

In Secs. III A and III B, we report examples of microand nanomechanical testing of metallic specimens that highlight the capabilities of the methods and instrumentation of our approach in the context of size dependent plasticity.

\section{A. Tensile testing of individual single crystal nanowires}

Using the approaches described above, an individual single crystalline copper nanowire with a diameter of $\sim 75 \mathrm{~nm}$ was extracted and transferred to the nanomechanical testing system. These nanowires are grown using high temperature physical vapor deposition onto a carbon-coated silicon substrate, resulting in single crystalline high-aspect ratio nanostructures with well-defined cross-sectional geometry, as reported by Richter et al. ${ }^{36}$ The remarkable defect- free nature and concomitant high strength (near the ideal strength) of these nanowires resulted in dubbing these structures nanowhiskers; adopted from the microwhisker experiments from fifty years ago by Brenner. ${ }^{68,94-97}$

Figure 6 shows snapshots of an in situ tensile test of the $75 \mathrm{~nm} \mathrm{Cu}$ nanowhisker. Figure 6(a) shows the initial testing configuration, demonstrating some natural contrast along the length of the nanowhisker, presumably from a carbonaceous layer that has formed as a result of imaging. This allows for a local and quasi-full field analysis of the strain that develops upon the application of load to the nanowhisker specimen. The axial displacement fields are shown in Figs. 6(b)6(d), which demonstrates that the largest gradients are directly along the nanowhisker axis, suggesting good alignment. In addition, the axial gradient (used to calculate axial strain) is uniform, which shows that plastic deformation in these $\mathrm{Cu}$ nanowhiskers does not result in localized necks or heavily slipped regions. Instead, deformation is primarily elastic until the point of fracture at strengths near the ideal strength, which is consistent with the notion of deformation of near defect-free nanostructures where nucleation of defects, rather than activation of pre-existing defects, is the strength controlling mechanism. ${ }^{98,99}$ Figure 6(e) shows an example of a tensile load-displacement curve measured from an individual Au nanowhisker with an effective diameter of $133 \mathrm{~nm}$, which demonstrates significant amounts of plastic strain. Knowledge of the cross-sectional area allows for the calculation of engineering stress, and the nominal strain in the wire is also shown. Using the system described herein, we have successfully measured the mechanical response of nanowire specimens as small as $60 \mathrm{~nm}$ in diameter. ${ }^{36}$

\section{B. Microcompression of nanoporous gold}

Figure 7 shows in situ microcompression of nanoporous Au specimens in a dual-beam FIB/SEM instrument. Focused ion beam milling using top-down annular patterns was employed to fabricate pillars from bulk nanoporous gold, prepared using chemical dealloying of $\mathrm{Au}-\mathrm{Ag}$ alloys following the procedure detailed in Refs. 100-102. For the in situ experiments, micropillars were fabricated so that the annular milling ring intersected with the edge of the bulk specimen as shown in Fig. 7(a). This enabled direct visualization of the micropillar perpendicular to the top surface during deformation (Figs. 7(d) and 7(e)), which greatly simplifies alignment of the flat punch tip and the specimen, in addition to interpretation and strain measurement.

The diamond punch was brought into close proximity to the specimen using the nanopositioning system, and the alignment was verified by performing multiple indents into the surface of the nanoporous Au away from the micropillar specimens. Inspection of the residual imprints on the surface indicates the degree of misalignment, which can be corrected by using the rotation axis of the microscope stage. Once aligned, the tip is brought to the specimen as shown in Fig. 7(d). To optimize image quality and signal-to-noise ratio, the test was performed in a step-wise fashion. Operating in feedback-enabled displacement control, $50 \mathrm{~nm}$ displacement 


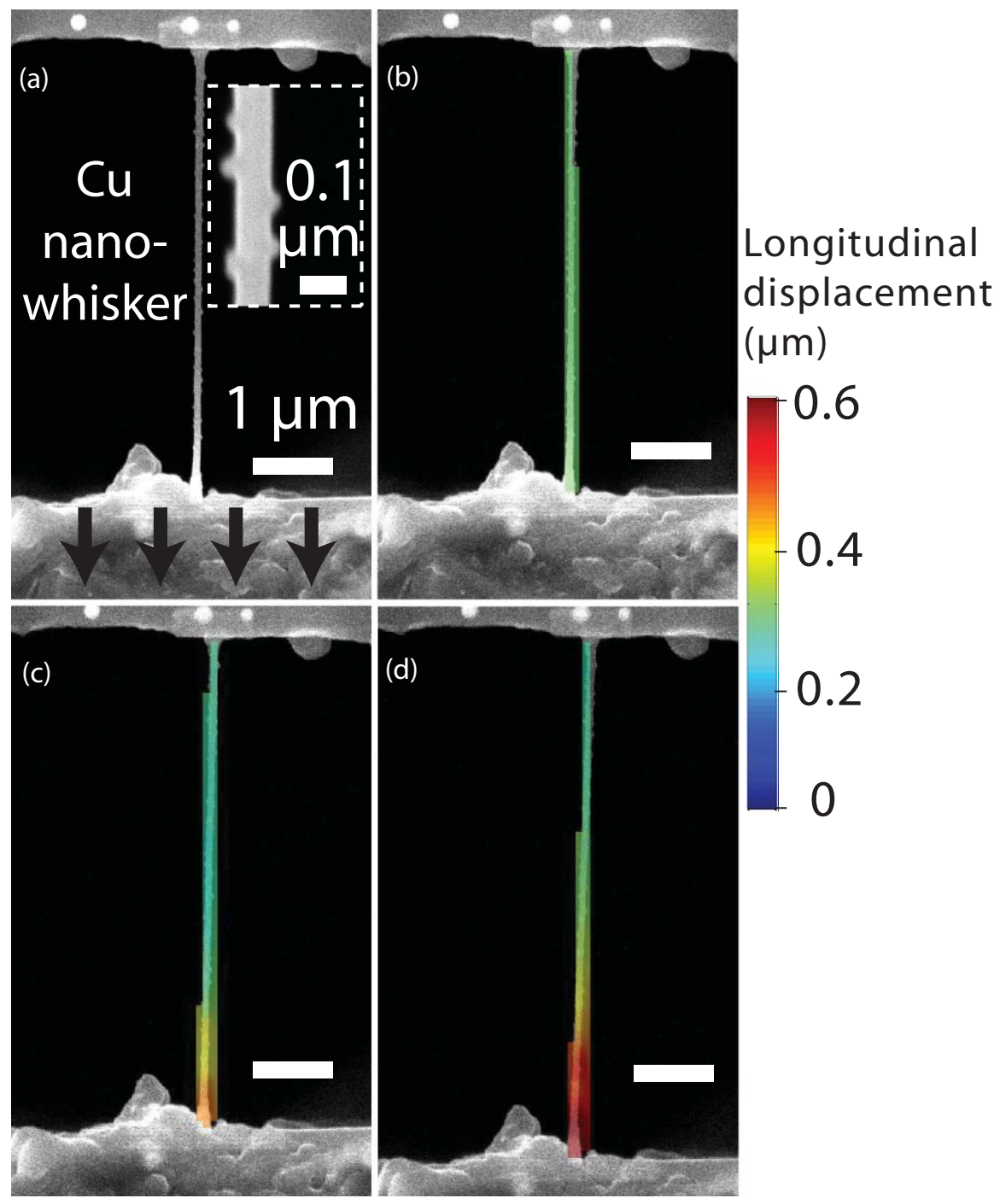

(e)

Nominal Engineering Strain

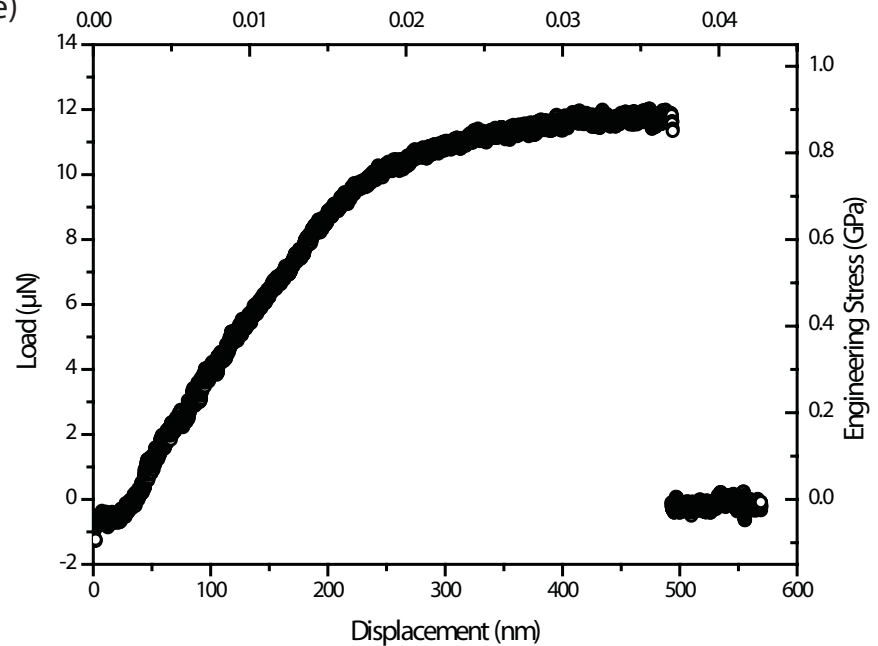

FIG. 6. (Color online) In situ tensile testing of $\mathrm{Cu}$ nanowhisker with a diameter of $75 \mathrm{~nm}$. (a) Cu Nanowhisker prior to testing. Inset shows features on wire surface used as contrast for digital image correlation. The attachment point at the bottom of image is the moving transducer probe. (b-d) Sequence during tensile testing with superimposed longitudinal displacement fields computed using digital image correlation. (e) Tensile load-displacement curve for an individual single crystalline Au nanowhisker with a diameter of $133 \mathrm{~nm}$. The point of fracture is indicated by the sudden drop in load at $\sim 500 \mathrm{~nm}$ of actuator displacement. 

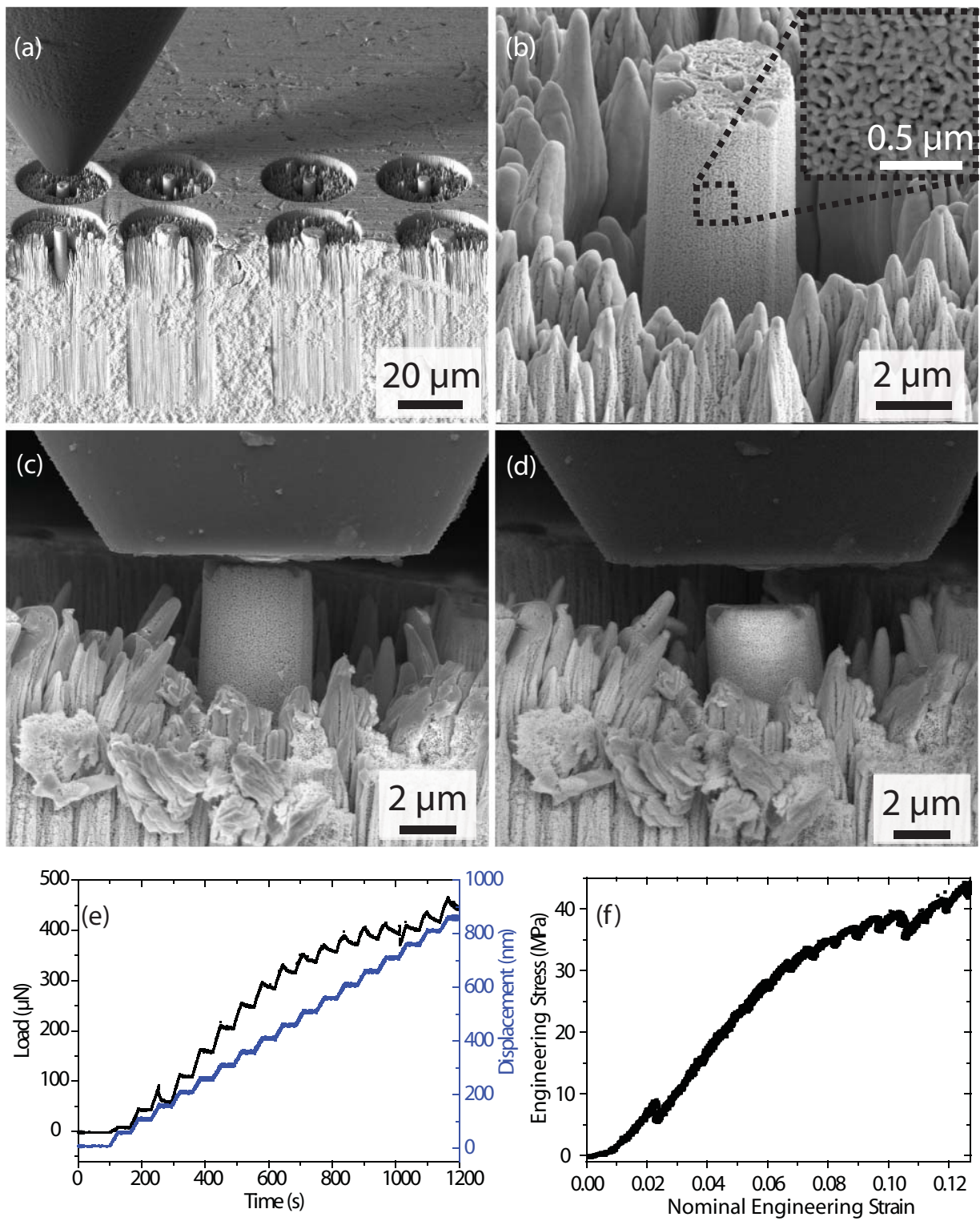

FIG. 7. (Color online) In situ compression of nanoporous Au micropillars fabricated using FIB annular milling (a). (b) SEM image of an individual pillar, showing the nanoporous structure which is magnified in the inset. In situ compression configuration (c) prior to testing and (d) after plastic deformation of the pillar. (e) Load and displacement vs. time showing the displacement holds for slow scan imaging. (f) Engineering stress vs. nominal engineering strain, which is estimated as the transducer displacement divided by the original height of the pillar.

increments were applied, followed by $\sim 50$ s hold segments. Relatively long dwell times were chosen for imaging during these displacement holds, and imaging was synchronized with the testing program. Figure 7(c) shows a snapshot of an image during testing, and the load-displacement data are shown in Fig. 7(e). It is evident from the load vs. time trace that significant load relaxation occurs during some of the displacement hold segments during testing. We speculate that these load transients could be related to microplasticity of regions near the base of the micropillar. Global plasticity of the micropillar can be seen in the load-displacement curve by the average curvature of the load curve during loading segments, as well as from a permanent shape change of the pillar shown in Fig. 7(d). While the majority of plastic deformation was concentrated in the lower half of this micropillar, which was partially shadowed by nanoporous Au residue surrounding the pillar, this approach provided high quality images capa- ble of detecting strain information at near local cellular architecture level. Studies are underway to provide a correlation between local structural deformation with macroscopic mechanical response, which show promise for testing the validity of Gibson-Ashby type scaling relationships as applied to the deformation of nanoporous metals. ${ }^{48,49,100-104}$

\section{CONCLUSION AND OUTLOOK}

We have shown the development and application of a quantitative in situ nanomechanical testing system designed for a scanning electron and focused ion beam platform. This system, based on a double three-plate capacitance actuation and sensing scheme with active feedback electronics for close-loop operation, can be utilized for several types of nanomechanical tests including tension, compression, bending, and indentation. In conjunction with the use of image 
processing software, the system allows for a quantitative assessment of the elastic and plastic response of nanostructures. We demonstrate the efficacy of this characterization platform to the in situ mechanical testing of metal nanowires and FIBfabricated nanoporous Au micropillars. The application of these quantitative methods allows for insights to be gleaned on new mechanisms of deformation that govern the mechanical response of small-scale materials.

We envision several future improvements to the nanomechanical testing system for increased fidelity and versatility. First, the overall size of the transducer and transducer housing will be reduced to minimize the risk of mechanical interference with other internal components and to facilitate the use of other in situ analytical techniques (e.g., EBSD). Through clever design, this can be accomplished without compromising the maximum transducer force. Another improvement will involve reducing the moving mass and/or increasing the spring stiffness of the transducer to in turn increase the resonance frequency and mechanical bandwidth of the transducer. A higher resonance frequency will offer faster response and also be more stable in the high vacuum environment. However, increasing the spring stiffness will place more demand on displacement sensitivity to not degrade the force sensitivity.

\section{ACKNOWLEDGMENTS}

The authors thank Gunther Richter for providing metal nanowhiskers. Thanks go to Haijun Jin and Simone Schendel for providing nanoporous Au specimens and preparing the pillars. D.S.G. acknowledges support from an Alexander von Humboldt Postdoctoral Fellowship and start-up funding from the University of Pennsylvania.

${ }^{1}$ M. D. Uchic, D. M. Dimiduk, J. N. Florando, and W. D. Nix, Science 305, 986 (2004).

${ }^{2}$ D. M. Dimiduk, M. D. Uchic, and T. A. Parthasarathy, Acta Mater. 53, 4065 (2005).

${ }^{3}$ J. R. Greer, W. C. Oliver, and W. D. Nix, Acta Mater. 53, 1821 (2005).

${ }^{4}$ C. A. Volkert and E. T. Lilleodden, Philos. Mag. 86, 5567 (2006).

${ }^{5}$ D. Kiener, C. Motz, T. Schöberl, M. Jenko, and G. Dehm, Adv. Eng. Mater. 8, 1119 (2006).

${ }^{6}$ S. Brinckmann, J.-Y. Kim, and J. Greer, Phys. Rev. Lett. 100, 155502 (2008).

${ }^{7}$ W. W. Gerberich, J. Michler, W. M. Mook, R. Ghisleni, F. Östlund, D. D. Stauffer, and R. Ballarini, J. Mater. Res. 24, 898 (2009).

${ }^{8}$ A. Jennings and J. Greer, Philos. Mag. 1108, 1 (2010).

${ }^{9}$ A. T. Jennings, M. J. Burek, and J. R. Greer, Phys. Rev. Lett. 104, (2010).

${ }^{10}$ J.-Y. Kim and J. R. Greer, Appl. Phys. Lett. 93, 101916 (2008).

${ }^{11}$ C. Motz, D. Weygand, J. Senger, and P. Gumbsch, Acta Mater. 56, 1942 (2008).

${ }^{12}$ A. Schneider, D. Kaufmann, B. Clark, C. Frick, P. Gruber, R. Mönig, O. Kraft, and E. Arzt, Phys. Rev. Lett. 103, (2009).

${ }^{13}$ B. E. Schuster, Q. Wei, T. C. Hufnagel, and K. T. Ramesh, Acta Mater. 56, 5091 (2008)

${ }^{14}$ C. A. Volkert, A. Donohue, and F. Spaepen, J. Appl. Phys. 103, 083539 (2008).

${ }^{15}$ D. S. Gianola and C. Eberl, JOM 61, 24 (2009).

${ }^{16}$ W. C. Oliver and G. M. Pharr, J. Mater. Res. 19, 3 (2004)

${ }^{17}$ M. Uchic, P. Shade, and D. Dimiduk, Annu. Rev. Mater. Res. 39, 361 (2009).

${ }^{18}$ O. Kraft, P. Gruber, R. Mönig, and D. Weygand, Annu. Rev. Mater. Res. 40, 293 (2010).

${ }^{19}$ M. D. Uchic, D. M. Dimiduk, R. Wheeler, P. A. Shade, and H. L. Fraser, Scr. Mater. 54, 759 (2006).
${ }^{20}$ S. T. Motz C and P. R, Acta Mater. 53, 4269 (2005).

${ }^{21}$ F. Weber, I. Schestakow, F. Roters, and D. Raabe, Adv. Eng. Mater. 10, 737 (2008).

${ }^{22}$ B. Wu, A. Heidelberg, and J. J. Boland, Nat. Mater. 4, 525 (2005).

${ }^{23}$ D. Kiener, W. Grosinger, G. Dehm, and R. Pippan, Acta Mater. 56, 580 (2008).

${ }^{24}$ K. J. Hemker and W. N. Sharpe, Annu. Rev. Mater. Res. 37, 93 (2007).

${ }^{25}$ W. N. Sharpe, K. T. Turner, and R. L. Edwards, Exp. Mech. 39, 162 (1999).

${ }^{26}$ Y. Ganesan, Y. Lu, C. Peng, H. Lu, R. Ballarini, and J. Lou, J. Microelectromech. Syst. 19, 675 (2010).

${ }^{27}$ Sé. Gravier, M. Coulombier, A. Safi, N. Andre, A. BoÉ, J.-P. Raskin, and T. Pardoen, J. Microelectromech. Syst. 18, 555 (2009).

${ }^{28}$ D. Zhang, J.-M. Breguet, R. Clavel, V. Sivakov, S. Christiansen, and J. Michler, J. Microelectromech. Syst. 19, 663 (2010).

${ }^{29}$ C. Ke and H. D. Espinosa, Small 2, 1484 (2006).

${ }^{30}$ B. Peng, M. Locascio, P. Zapol, S. Li, S. L. Mielke, G. C. Schatz, and H. D. Espinosa, Nat. Nanotech. 3, 626 (2008).

${ }^{31}$ Y. Zhu, C. Ke, and H. D. Espinosa, Exp. Mech. 47, 7 (2007).

${ }^{32}$ I. Chasiotis and W. Knauss, Exp. Mech. 42, 51 (2002).

${ }^{33}$ M. Naraghi, T. Ozkan, I. Chasiotis, S. Hazra, and M. de Boer, J. Micromech. Microeng. 20, 125022 (2010).

${ }^{34}$ U. Singh, V. Prakash, A. R. Abramson, W. Chen, L. Qu, and L. Dai, Appl. Phys. Lett. 89, 073103 (2006).

${ }^{35}$ S. Orso, U. G. K. Wegst, C. Eberl, and E. Arzt, Adv. Mater. 18, 874 (2006).

${ }^{36}$ G. Richter, K. Hillerich, D. S. Gianola, R. Mönig, O. Kraft, and C. A. Volkert, Nano Lett. 9, 3048 (2009).

${ }^{37}$ M. Legros, D. Gianola, and C. Motz, MRS Bull. 35, 354 (2010).

${ }^{38}$ K. A. Rzepiejewska-Malyska, G. Buerki, J. Michler, R. C. Major, E. Cyrankowski, S. A. S. Asif, and O. L. Warren, J. Mater. Res. 23, 1973 (2008).

${ }^{39}$ J. Michler, K. Wasmer, S. Meier, F. Östlund, and K. Leifer, Appl. Phys. Lett. 90, 043123 (2007).

${ }^{40}$ J. Nowak, K. Rzepiejewska-Malyska, R. Major, O. Warren, and J. Michler, Mater. Today 12, 44 (2010).

${ }^{41}$ A. M. Minor, E. T. Lilleodden, M. Jin, E. A. Stach, D. C. Chrzan, and J. W. M. Jr, Philos. Mag. 85, 323 (2005).

${ }^{42}$ A. M. Minor, E. T. Lilleodden, E. A. Stach, and J. W. M. Jr, J. Mater. Res. 19, 176 (2004).

${ }^{43}$ A. M. Minor, S. A. S. Asif, Z. Shan, E. A. Stach, E. Cyrankowski, T. J. Wyrobek, and O. L. Warren, Nat. Mater. 5, 697 (2006).

${ }^{44}$ S. H. Oh, M. Legros, D. Kiener, and G. Dehm, Nat. Mater. 8, 95 (2009).

${ }^{45}$ Z. W. Shan, R. K. Mishra, S. A. Syed Asif, O. L. Warren, and A. M. Minor, Nat. Mater. 7, 115 (2008)

${ }^{46}$ Z. W. Shan, G. Adesso, A. Cabot, M. P. Sherburne, S. A. Syed Asif, O. L. Warren, D. C. Chrzan, A. M. Minor, and A. P. Alivisatos, Nat. Mater. 7, 947 (2008).

${ }^{47}$ Z. W. Shan, J. Li, Y. Q. Cheng, A. M. Minor, S. A. Syed Asif, O. L. Warren, and E. Ma, Phys. Rev. B 77, 155419 (2008).

${ }^{48}$ Y. Sun, J. Ye, A. M. Minor, and T. J. Balk, Microsc. Res. Tech. 72, 232 (2009).

${ }^{49}$ Y. Sun, J. Ye, Z. Shan, A. M. Minor, and T. J. Balk, JOM J. Miner., Met. Mater. Soc. 59, 54 (2007).

${ }^{50}$ Y. B. Wang, B. Q. Li, M. L. Sui, and S. X. Mao, Appl. Phys. Lett. 92, 011903 (2008).

${ }^{51}$ J. Ye, R. K. Mishra, A. R. Pelton, and A. M. Minor, Acta Mater. 58, 490 (2010).

${ }^{52}$ M. Legros, M. Cabie, and D. S. Gianola, Microsc. Res. Tech. 72, 270 (2009).

${ }^{53}$ J. Deneen, W. M. Mook, A. Minor, W. W. Gerberich, and C. Barry Carter, J. Mater. Sci. 41, 4477 (2006).

${ }^{54}$ X. Li, I. Chasiotis, and T. Kitamura, MRS Bull. 35, 361 (2010).

${ }^{55}$ R. Spolenak, W. Ludwig, J. Buffiere, and J. Michler, MRS Bull. 35, 368 (2010).

${ }^{56}$ R. Maaß, S. Van Petegem, D. Grolimund, H. Van Swygenhoven, D. Kiener, and G. Dehm, Appl. Phys. Lett. 92, 071905 (2008).

${ }^{57}$ R. Maaß, S. Van Petegem, H. Van Swygenhoven, P. Derlet, C. Volkert, and D. Grolimund, Phys. Rev. Lett. 99, 145505 (2007).

${ }^{58} \mathrm{~K}$. Wasmer, T. Wermelinger, A. Bidiville, R. Spolenak, and J. Michler, J. Mater. Res. 23, 3040 (2008).

${ }^{59}$ American Society of Testing and Materials, ASTM E 8M, 1995.

${ }^{60}$ M. A. Haque and M. T. A. Saif, Scr. Mater. 47, 863 (2002). 
${ }^{61}$ T. E. Buchheit, S. J. Glass, J. R. Sullivan, S. S. Mani, D. A. Lavan, T. A. Friedmann, and R. Janek, J. Mater. Sci. 38, 4081 (2003).

${ }^{62}$ W. N. Sharpe, B. Yuan, and R. L. Edwards, J. Microelectromech. Syst. 6, 193 (1997).

${ }^{63}$ E. P. S. Tan and C. T. Lim, Rev. Sci. Instrum. 75, 2581 (2004).

${ }^{64}$ H. Miyazaki and K. Hayashi, Biomed. Microdevices 2, 151 (1999).

${ }^{65}$ M. F. Yu, O. Lourie, M. J. Dyer, K. Moloni, T. F. Kelly, and R. S. Ruoff, Science 287, 637 (2000).

${ }^{66}$ M. D. Wang, H. Yin, R. Landick, J. Gelles, and S. M. Block, Biophys. J. 72, 1335 (1997)

${ }^{67}$ H. D. Espinosa, B. C. Prorok, and M. Fischer, J. Mech. Phys. Solids 51, 47 (2003).

${ }^{68}$ S. S. Brenner, J. Appl. Phys. 27, 1484 (1956).

${ }^{69}$ R. Longtin, C. Fauteux, J. Pegna, and M. Boman, Carbon 42, 2905 (2004).

${ }^{70}$ W. Suwito, M. Dunn, S. Cunningham, and D. Read, J. Appl. Phys. 85, 3519 (1999).

${ }^{71}$ T. Zhang, Y. Su, C. Qian, M. Zhao, and L. Chen, Acta Mater. 48, 2843 (2000).

${ }^{72}$ C. A. Volkert and A. M. Minor, MRS Bull. 32, 389 (2007).

${ }^{73}$ H. Hiroshima, N. Suzuki, N. Ogawa, and M. Komuro, Jpn. J. Appl. Phys., Part 1 38, 7135 (1999).

${ }^{74}$ V. Gopal, V. Radmilovic, C. Daraio, S. Jin, P. Yang, and E. Stach, Nano Lett. 4, 2059 (2004).

${ }^{75}$ Introduction to Focused Ion Beams: Instrumentation, Theory, Techniques and Practice, edited by F. A. S. L. A. Giannuzzi (Springer, New York, 2005).

${ }^{76}$ H. Bei, S. Shim, M. K. Miller, G. M. Pharr, and E. P. George, Appl. Phys. Lett. 91, 111915 (2007)

${ }^{77}$ B. Moser, K. Wasmer, L. Barbieri, and J. Michler, J. Mater. Res. 22, 1004 (2007).

${ }^{78}$ M. D. Uchic and D. M. Dimiduk, Mater. Sci. Eng. A 400-401, 268 (2005).

${ }^{79}$ V. Gopal, E. Stach, V. Radmilovic, and I. Mowat, Appl. Phys. Lett. 85, 49 (2004).

${ }^{80}$ I. Utke, V. Friedli, S. Fahlbusch, S. Hoffmann, P. Hoffmann, and J. Michler, Adv. Eng. Mater. 8, 155 (2006).

${ }^{81}$ O. Warren, S. Downs, and T. Wyrobek, Z. Metallkd. 95, 287 (2004).

${ }^{82}$ Y. Oh, M. R. Wilson, R. C. Major, S. A. S. Asif, and O. L. Warren, U.S. Patent No. US 2010/0036636 A1 (2010).
${ }^{83}$ M. A. Sutton, J.-J. Orteu, and H. Schreier, Image Correlation for Shape, Motion and Deformation Measurements: Basic Concepts, Theory and Applications, 1st ed. (Springer, New York, 2009).

${ }^{84}$ T. C. Chu, W. F. Ranson, M. A. Sutton, and W. H. Peters, Exp. Mech. 25, 232 (1985).

${ }^{85}$ W. H. Peters and W. F. Ranson, Opt. Eng. 21, 427 (1982).

${ }^{86}$ H. A. Bruck, S. R. McNeill, M. A. Sutton, and W. H. P. III, Exp. Mech. 29, 261 (1989).

${ }^{87}$ W. N. Sharpe, J. Pulskamp, D. S. Gianola, C. Eberl, R. Polawich, and R. Thompson, Exp. Mech. 47, 649 (2006).

${ }^{88}$ C. Eberl, D. S. Gianola, and R. Thompson, MATLAB file exchange, http://www.mathworks.com/matlabcentral/fileexchange/12413 (2006).

${ }^{89}$ N. Biery, M. de Graef, and T. Pollock, Metall. Mater. Trans. A 34, 2301 (2003).

${ }^{90}$ M. A. Sutton, N. Li, D. C. Joy, A. P. Reynolds, and X. Li, Exp. Mech. 47, 775 (2007).

${ }^{91}$ M. A. Sutton, N. Li, D. Garcia, N. Cornille, J. J. Orteu, S. R. McNeill, H. W. Schreier, X. Li, and A. P. Reynolds, Exp. Mech. 47, 789 (2007).

${ }^{92}$ B. G. Clark, D. S. Gianola, O. Kraft, and C. P. Frick, Adv. Eng. Mater. 12, 808 (2010).

${ }^{93}$ W. A. Scrivens, Y. Luo, M. A. Sutton, S. A. Collette, M. L. Myrick, P. Miney, P. E. Colavita, A. P. Reynolds, and X. Li, Exp. Mech. 47, 63 (2006).

${ }^{94}$ S. S. Brenner, Acta Metall. 4, 62 (1956).

${ }^{95}$ S. S. Brenner, J. Appl. Phys. 28, 1023 (1957).

${ }^{96}$ S. S. Brenner, J. Appl. Phys. 30, 266 (1958).

${ }^{97}$ S. S. Brenner and G. W. Sears, Acta Metall. 4, 268 (1956).

${ }^{98}$ H. Bei, S. Shim, E. P. George, M. K. Miller, E. G. Herbert, and G. M. Pharr, Scr. Mater. 57, 397 (2007).

${ }^{99}$ T. Zhu, J. Li, A. Samanta, A. Leach, and K. Gall, Phys. Rev. Lett. 100, 025502 (2008).

${ }^{100}$ C. A. Volkert, E. T. Lilleodden, D. Kramer, and J. Weissmüller, Appl. Phys. Lett. 89, 061920 (2006).

${ }^{101}$ J. Biener, A. M. Hodge, J. R. Hayes, C. A. Volkert, L. A. Zepeda-Ruiz, A. V. Hamza, and F. F. Abraham, Nano Lett. 6, 2379 (2006).

${ }^{102}$ C. A. Volkert and E. T. Lilleodden, Philos. Mag. 86, 5567 (2006).

${ }^{103}$ T. J. Balk, C. Eberl, Y. Sun, K. J. Hemker, and D. S. Gianola, JOM J. Miner., Met. Mater. Soc. 61, 26 (2009).

${ }^{104}$ A. Mathur and J. Erlebacher, Appl. Phys. Lett. 90, 061910 (2007). 